\title{
Resin Modified Glass Ionomer Liner
}

National Cancer Institute

\section{Source}

National Cancer Institute. Resin Modified Glass Ionomer Liner. NCI Thesaurus. Code C52585.

A dental restorative material made up of disparate or separate parts (e.g., resin and quartz particles) in a glass polyalkenoate cement (a fluoride-containing aluminosilicate glass powder) used as a liner/base for other restoration materials. 